\title{
Designing for thermal comfort near a glazed exterior wall
}

\author{
T.N. Anderson ${ }^{\ddagger *}$, M.B. Luther ${ }^{* *}$ \\ * School of Engineering, Auckland University of Technology, Auckland, New Zealand \\ ** School of Architecture and Building, Deakin University, Geelong, Australia
}

\begin{abstract}
In many highly glazed buildings, the thermal comfort of the occupants will tend to be related to the incoming solar energy and the heat transfer behaviour of the glazing. In this study, several glazing systems were designed using the software tools VISION 3 (University of Waterloo, 1992) and WINDOW-6 (Lawrence Berkeley National Laboratory, 2011), with a view to improving thermal environment of occupants near the glazed wall of a commercial office. The systems were fabricated and experimentally tested to validate the software modelling results. Subsequently the glazing systems were retro-fitted to the office and tested in-situ for a summer month. Results of this testing, in the form of Fangers' predicted mean vote (PMV) and the predicted percentage dissatisfied (PPD), are presented, and some options for improving the thermal environment in this near-facade zone are discussed.
\end{abstract}

Keywords: design, glazing, modelling, thermal comfort, testing

‡ Corresponding Author: Tel.: +64 99219999 Extension 8075

E-mail address: timothy.anderson@aut.ac.nz 


\section{Introduction}

The idea of human thermal comfort is one that is particularly complex, however, at its most basic it can be defined as "that condition of mind which expresses satisfaction with the thermal environment” (ISO 7730, 2005). Therefore the idea of someone being "comfortable" relates not just to the air temperature but also to a range of other nonenvironmental parameters such as physiology, psychology and behavioural factors. As such, comfort is a complex relationship between, parameters such as metabolic rates, the level of clothing being worn, air temperature, relative humidity, mean radiant temperature, local air velocity and radiant asymmetry.

Fanger (1973) developed a quantitative method (the "Comfort Equation”) to describe comfort levels using six parameters as shown in Equation 1.

$$
f\left(M, C l o, v, t_{r}, t_{\alpha^{\prime}}, P_{w}\right)=0
$$

Where $M$ is the metabolic rate, Clo is a clothing index, $v$ the air velocity $(\mathrm{m} / \mathrm{s}), t_{r}$ is the mean radiant temperature $\left({ }^{\circ} \mathrm{C}\right), t_{a}$ the ambient air temperature $\left({ }^{\circ} \mathrm{C}\right)$ and $P_{w}$ is the vapour pressure of water in ambient air $(\mathrm{Pa})$. When any combination of these parameters satisfies the comfort equation the thermal comfort of the majority of occupants will be neutral, i.e. not too hot nor too cold.

In reality, it is not always possible to satisfy this criterion and so have "optimal" thermal comfort. As such it is necessary to describe the relative level of discomfort. This can be 
achieved by two quantitative means: the Predicted Mean Vote (PMV) Index and the Predicted Percentage Dissatisfied (PPD) Index (Fanger, 1973). The PMV index predicts the mean response of a large group of people according to the ASHRAE thermal sensation scale and results in a rating from +3 (hot) to -3 (cold). This PMV value is a function of the metabolic rate $(M)$ and thermal load (Equation 2), where the thermal load $(L)$ is defined as: the difference between the internal heat production and the heat loss to the actual environment for a person kept at comfortable values of skin temperature and evaporative heat loss by sweating at their actual activity level.

$$
P M V=\left(0.303 e^{-0.036 M}+0.028\right) L(2)
$$

The second criterion, PPD, is a quantitative measure of the thermal comfort of a group of people in a particular thermal environment and is a more meaningful indicator of thermal comfort. Fanger (1973) related the PPD to the PMV using Equation 3.

$$
P P D=100-95 e^{-\left(0.03353 P M V^{2}+0.2179 P M V^{2}\right)}
$$

What Fanger (1973) found from the PPD, was that irrespective of how perfect a thermal environment is, it is not possible to achieve a PPD of less than $5 \%$ for similarly clothed people undertaking the same activity.

Previously, work had been undertaken into the indoor environmental quality testing of a commercial office building in a refurbished wool-store, shown in Figure 1. During this investigation it was found that occupants near the single glazed eastern perimeter of the 
building reported a higher degree of discomfort than those situated in the interior workplace. One of the improvements made was the introduction of an optimized conditioning control system that attempted to balance the temperature throughout the open office space.

\section{FIGURE 1}

However, several years later, the management and occupants of this building remain dissatisfied with the thermal conditioning near the glazed perimeter, particularly on extremely hot days. As such, the building occupants were interested in investigating solutions to the problem that could improve thermal comfort, but not unduly disturb the aesthetic qualities of the existing facade.

Therefore, the objective of the study was to investigate possible solutions such that the occupants could work in a comfortable temperature range, particularly near the eastern

perimeter (Figure 2) where there exists a three-metre floor-to-ceiling single glazed façade with a selective mirror-faced external coating and a heat absorbing glass.

\section{FIGURE 2}

Given that previous attempts to rectify the situation in the building were aimed at modifying the air velocity $(v)$, interior temperature $\left(t_{a}\right)$ and relative humidity $\left(P_{w}\right)$ for Fangers' Comfort Equation, this study focussed on addressing the affect of the radiant temperature encountered by the buildings occupants ( $\mathrm{t}_{\mathrm{r}}$ in Fangers' Comfort Equation). 


\section{Heat Transfer in Glazing}

Given that occupants of the office near the glazed facade of the building complained of greater discomfort than those situated in the interior workplace, and the possible effect of the radiant temperature, it is important to understand the mechanisms of heat transfer that are occurring to (and from) the glass and how they are defined.

The heat gains or losses to a glazing system are related to the physical properties of glass (conductivity, absorption, reflection, and transmittance) and are a function of the environmental conditions (solar radiation, wind and external/internal air temperatures). Predicting the heat gain or heat loss from a glass façade system is ultimately dependent upon the calculation of the glass surface temperature. In other words, after the physical properties are accounted for with respect to the environmental conditions, we can determine the glass' surface temperature. Once the temperature is calculated, it is possible to calculate the amount of heat transfer from, or to, the glazing by the buildings occupants by conduction, convection and radiation (Duffie and Beckman, 2005).

The instantaneous transfer of heat to and from a glazing system is represented by three components as illustrated in Figure 3.

FIGURE 3 
As such, the overall transfer of heat can then be described by Equation 3 (ASHRAE, 2005):

$$
q_{A}=I_{t} \tau+N_{i}\left(\alpha I_{t}\right)+U\left(\mathrm{t}_{\mathrm{o}}-\mathrm{t}_{\mathrm{i}}\right)
$$

Where $q_{A}$ is the total inward heat gain through the glass $\left(\mathrm{W} / \mathrm{m}^{2}\right), I_{t}$ is the incident solar radiation available on the exterior glass $\left(\mathrm{W} / \mathrm{m}^{2}\right), \tau$ is the fraction of $I_{t}$ which is directly transmitted through the glass, $N_{i}$ is the inward-flowing fraction of absorbed solar radiation, $\alpha$ is the fraction of $I_{t}$ which is absorbed within the glass, $U$ is the total thermal conductance of the glazing unit $\left(\mathrm{W} / \mathrm{m}^{2} \mathrm{~K}\right), t_{o}$ is the exterior or outside (ambient) air temperature $(\mathrm{K})$ and $t_{i}$ is the interior air temperature $(\mathrm{K})$.

In examining Equation 3, the coefficients of the first and second terms $\left(I_{t} \tau+N_{i}\left(\alpha I_{t}\right)\right)$, represents the Solar Heat Gain Coefficient (SHGC) of the glass. This is the transfer of heat from the solar irradiated glass to the occupied space. The third term $\left(U\left(t_{o}-t_{i}\right)\right)$ represents the overall conductive heat transfer through the glass considering the differences between the interior and exterior temperature only. In this respect, if the interior and exterior air temperatures are equal, the conductive term reduces to zero allowing only the heat gains due to radiation to occur.

Lastly, the ratio of the Solar Heat Gain Coefficient (SHGC) of a specific glazing unit to that of a standard double strength A-grade (DSA) glass (a clear architectural glass 3mm thick) provides the Shading Coefficient. Usually all other glazing systems are less than 
unity when compared to a DSA glass and so low SC's are an indication of the glazing systems capability to reduce incident solar heat gain transfer into a building.

In summary, U-Value, Solar Heat Gain Co-efficient (SHGC) and Shading Co-efficient (SC) could characterise the thermal comfort that may be encountered near glazing systems, as these coefficients relate to heat transfer through a glazing system.

\section{Modelling Heat Transfer in the Glass Façade}

In light of the dissatisfaction with the thermal environment near the glass façade, and the possibility of it being linked to the temperature and solar transmission of the glazing system, three alternatives were proposed to help remedy the issue.

Firstly it was proposed that a shading screen fabricated from a protruded 3-D microscreen, situated on an external frame, be installed 50mm from the existing glass facade. Secondly, it was suggested that an argon-filled insulating glazing (IG) unit consisting of a clear and a low-e glass be assembled on the interior of the existing façade, thus providing a triple glazed façade with the low-e surface on the cavity side of the interior glass. Finally, the third solution was to utilise another argon filled IG unit with the centre glass being a heat absorbing grey glass and again forming a tripled glazed low-e system.

The rationale for the three alternatives was to explore options that could lead to a reduction of the mean radiant temperature from the glazing surface as well as the 
transmitted solar energy. In the first instance a shading device would block out large percentages of radiation reaching the glass, yielding a lower surface temperature and resulting in a cooler building air temperature, through reduced radiant and convective gains. As the shading device was not expected to lower the U-Value of the glass it was anticipated that the building might still be too cold during winter periods. However shading offers to reduce solar heat gains in periods of extreme temperature (Tzempelikos et al, 2010).

In the second situation, triple glazed units with a gas fill such as argon could provide an effective solution as such units would have a lower U-Value. Additionally, the introduction of a low-e coating could reduce radiant heat transfer from the window due to the higher infrared (long wave) reflectance of the coated surface. Triple glazed units have been found to minimize the overall inside air temperature variance of a building due to lower values of solar heat gain as well as loss (Fang et al, 2010). As such these units could help improve thermal comfort under high radiation and also during cold periods.

Having formulated three concepts for glazing to improve thermal comfort it was decided to utilise two readily available glazing analysis programs to determine the effect of design modifications on the façades thermal performance.

The first of these, VISION 3.0, was developed at the Advanced Glazing System Laboratory at the University of Waterloo in Canada (1992) and was used to predict the U-Value, SHGC and SC for the proposed systems. Additionally it was used to calculate 
the glass surface temperatures, absorbed radiation, transmitted radiation, the radiative and convective component of heat flux as well as the transmitted visible/solar ratio. The second software tool, WINDOW 6 a package developed at Lawrence Berkeley National Laboratory (2011) for analyzing window thermal performance in accordance with standard NRFC procedures, was also utilised in predicting the transient glass surface temperatures in the facade system.

\section{Original Glazing System}

The original glazing system consisted of a single layer of tinted glass (TS30), the transmittance $(\tau)$ and reflectance $(\rho)$ of which are shown in Table 1, for the visible, solar and long-wave spectrums. It is interesting to note that the original glazing system has a high emissivity value on its inner surface. This would suggest that the incident radiation absorbed by the glass would be radiatively transferred to office.

\section{TABLE 1}

Figure 4 provides a graphical summary of the VISION 3.0 predicted heat gains through the window (for the internal and external temperatures and radiation shown). From this, it can be seen that approximately $20 \%$ of the incident radiation $\left(147 \mathrm{~W} / \mathrm{m}^{2}\right)$ is transmitted into the building, corresponding to the solar transmittance.

However more importantly, it shows that the glass absorbs over $60 \%$ of the incident solar radiation. This leads to a significant increase in the glass temperature encouraging 
high rates of convective (C) heat transfer $\left(66.3 \mathrm{~W} / \mathrm{m}^{2}\right)$. Furthermore, the relatively high emissivity of the inner surface results in a large radiative $(\mathrm{R})$ heat transfer rate into the building $\left(77 \mathrm{~W} / \mathrm{m}^{2}\right)$.

\section{FIGURE 4}

What this modelling shows is that the original system has a high SHGC and SC. As such heat gains by the building will be high during high radiation times, and during colder periods the building will suffer heat losses due to a high U-Value and high emissivity. In turn if we consider this over a range of conditions (varying radiation, temperature and wind speed) using WINDOW 6, as shown in Figure 5, it can be seen that even at low radiation levels the glass' outside surface temperature may be significantly above the ambient temperature.

\section{FIGURE 5}

\section{Shaded Glazing System}

The first proposed solution for modifying the glazed facade was to provide a shading screen to the exterior of the glass facade. For the shaded glazing system the glass optical properties are the same as for the original glazing system, as the screen would be added to the exterior of this. However, for the simulations, it was assumed that the screen would result in an $85 \%$ decrease the incident solar radiation reaching the glass. 
Under this assumption, Figure 6 shows that by blocking a significant portion of the radiation from reaching the glazing that the glass temperature is substantially reduced from that of the original glazing system. In turn, the total heat gain is significantly less than the original glass and the inside glass surface temperature nearly $11^{\mathbb{Z}}$ cooler than the 'original' glass system. The net result of the screen is that the shading screen should lead to improvements in the SHGC and SC. However, the U-Value of the system is still relatively high, as the screen offers no real thermal resistance.

\section{FIGURE 6}

\section{Clear Triple Glazed System}

The second solution that was explored was a retrofit triple glazing unit. In this system, the original glazing was maintained and a double glazed unit, with a clear glass pane forming the middle pane of the triple glazed unit, was fitted behind this on the interior of the building. As such, this new system had varying glass properties between the three layers where the new middle and interior layers had high values of visible and solar transmittance and low values of visible and solar reflectance as shown in Table 2 . The use of a low-e coating on the outside of the interior layer of glass means the surface has a high longwave reflectance when compared to the other high emissivity surfaces.

\section{TABLE 2}


In Figure 7, with the clear triple glazed system, it can be seen that a high amount of the incident radiation is absorbed in the outside layer of the glass. This means that the interior surfaces absorb very little radiation and therefore the inside glass temperature is much lower than the original system. In this system about $10 \%$ of the incident radiation is still transmitted, but because of the lower temperature of the internal pane, heat gain due to convection and radiation into the room are significantly less. On this basis the overall system should perform better than the original system. Moreover, the clear triple glazing should have a much lower U-Value, SHGC and SC than the original glazing system meaning that it is reducing heat gain when ambient temperatures are hot and heat loss when ambient temperatures are cold.

FIGURE 7

\section{Grey Triple Glazed System}

The third solution that was explored was another retrofit triple glazing unit. Again, in this system a double-glazed unit, with a grey glass pane forming the middle pane of the triple glazed unit, was fitted behind the original glazing on the interior of the building. Table 3 shows the glass properties for the three layers, where the grey middle layer has low visible and solar transmittance compared to the clear glass in the previous system. The interior glass however remains a clear low-e glass, yielding high longwave reflectance on the outside of the interior glass.

TABLE 3 
Figure 8 illustrates the grey triple glazed system simulation results. In this system the middle grey glass layer absorbs a significant fraction of the remaining radiation through the outside layer, This results in a low absorption on the inside layer as a result of the low amount of transmitted radiation $(<5 \%)$. However, the absorption by the grey glass leads it to having a higher inside temperature than the clear triple glazed system and so a high rate of radiant heat transfer to the low-e pane. This leads to the inner pane having a higher temperature thereby resulting in a higher convective and radiant heat gain from the inside pane to the office space. In summary, this type of triple glazing should have lower values of SHGC and SC than the clear IG unit described previously but a higher U-Value due to the radiant properties of the grey layer of glass allowing more outward heat loss.

\section{FIGURE 8}

\section{Experimental Setup}

In order to further explore the findings from the model and its impact on thermal comfort, it was decided to conduct an in-situ experimental assessment of the three alternative glazing systems in conjunction with the original system.

In collecting meteorological data, a weather station assembled on the roof of an adjacent building adjacent was logged for the duration of the experiments. This station consisted of a pyranometer measuring global radiation on a horizontal plane and a HMP35C Temperature/Relative Humidity Probe to measure the air temperature, relative humidity 
and wind speed. This data was logged at 15-minute intervals using a CR10X Campbell Scientific data logger.

Additionally a LI-COR silicon pyranometer, was mounted on the facade of the building to measure the solar radiation incident on the windows. An array of calibrated $( \pm 0.3 \mathrm{~K})$ light gauge T-type thermocouples prepared for solar exposure, as suggested by Liu (1988), were used to measure the surface temperature of the glazing systems. Further radiant asymmetry sensors were placed approximately 500mm from the inside glazing to measure the radiant heat gain or loss from the windows.

To assess the comfort level of the occupants a 1221 Bruel \& Kjaer Comfort Meter, placed 500mm from the glazing, was used to measure the interior glass surface temperature, dry and wet bulb temperature, mean radiant temperature, absolute humidity, air velocity, operative temperature and the radiant asymmetry. The outputs were from these was used in determining thermal comfort parameters set out in ISO7730 (Fanger Model of comfort).

\section{Modelling Validation}

Having undertaken design calculations of the façade thermal performance using steady state software modelling tools, it was necessary to validate the findings from these models, and test them under transient conditions. As such the temperatures predicted by Vision and Window were examined, and found to be comparable. Subsequently, the experimentally measured incident solar radiation, ambient temperature, wind speed and 
internal air temperature for a range of conditions were input into WINDOW 6. From Figures 9 it can be seen that there was good correlation between the modelled and measured temperature on the inside of the original glazing system.

\section{FIGURE 9}

Similarly, Figure 10 shows good correlation between the modelled and measured inside glass surface temperature of the clear tripled glazed system, for most conditions. This suggests that even for multilayered glazing systems, steady state models are able to achieve a relatively satisfactory correlation with reality.

\section{FIGURE 10}

On this basis it can be concluded that the findings of the modelling are likely to be borne out practice. Those being: that the radiant heat transfer from the original glazing will be a large fraction of the inward flowing heat gain and that the use of low-e glasses can reduce the radiant transfer from the glass to the interior.

\section{Results}

To quantify the indoor comfort, a PMV and PPD calculation was made for each of the glazing options. This could be utilized to determine when the occupants were the least satisfied, and if the occupants were dissatisfied, was it because they perceived the building to be too cold or too hot. As the PPD is calculated from the measured values 
from the comfort meter including dry bulb temperature and air velocity, the instrument was placed adjacent to the east facing facade.

\section{Original Glazing System}

Before exploring the potential solutions, a benchmark assessment of the predicted percentage dissatisfied was performed on the existing glazed facade assuming a clothing index of 0.8 and a metabolic rate of 1.0, typical values for Australian office workers (Rowe, 2001), though perhaps conservative for summer conditions. That said, it should be noted that if the occupants clothing index were lower (0.65) given summer periods, and they had a higher metabolic rate (1.2) the results are comparable.

Figure 11 illustrates a period of warm weather with high incident radiation where the office air temperature near the facade reached nearly $30^{\circ} \mathrm{C}$. Such conditions cause the occupants to be quite dissatisfied, with around 30\% predicted to be dissatisfied with the thermal comfort in the building. In addition it can be seen that, relatively small changes in the inside temperature often lead to dramatic changes to the PPD. This illustrates that the original glazing system is not aiding the thermal environment, and that during hot summer conditions there would be a large percentage of the employees dissatisfied.

\section{FIGURE 11}

More importantly, before midday tends to be the worst time of day, as this is when the eastern face of the building is under high levels of incident solar radiation. However, 
once the building has been heated in the morning it stays warm all day, leaving occupants dissatisfied all day long. Furthermore, if the weather cools down it can be seen that the office can be perceived to be too cold.

\section{Shaded Glazing System}

As mentioned previously, a PMV and PPD calculation was made for each alternative system explored during this study. When examining, the PMV for the fixed shaded glazing system (Figure 12), it can be seen that the occupants are likely to be satisfied with their environment. It is interesting to note that during early office hours (c. 8:30) there is a period where occupants may feel slightly warm. This is also illustrated in the PPD assessment, Figure 13, where a brief period of increased dissatisfaction is predicted. However, it can be seen that as the indoor air temperature decreases, the PMV and PPD also decrease, suggesting the thermal comfort for the occupants with this glazing arrangement will be dominated by the mean radiant and indoor air temperature. Similarly, it is important to note that during the very early morning, the shaded system experiences a negative radiant asymmetry (radiant heat loss from the building). This

suggests that during cooler periods, the shaded glazing system could lead building occupants near the facade to feel cold.

FIGURE 12

FIGURE 13

Clear Triple Glazed System 
When examining, the predicted mean vote for the clear triple glazing system (Figure 14), it can be seen that the occupants are likely to feel slightly warm in their environment. Again in Figure 15 it can be seen that as the indoor air temperature decreases, the PMV and PPD also decrease, however it is interesting to observe that at approximately 9:00, there is a sharp increase in the predicted dissatisfaction, with only a slight change in the radiant asymmetry and indoor air temperature. This suggests that for this instance, the air temperature becomes less significant than other factors, such as radiant heat transfer from the glass. On the whole however, the relatively high temperature in the office suggests that air temperature is still a significant factor, and that perhaps the cooling system was not functioning appropriately.

FIGURE 14

FIGURE 15

\section{Grey Triple Glazed System}

When examining, the PMV for the grey triple glazing system (Figure 16), it can be seen that the occupants are again likely to feel slightly warm in their environment. In Figure 16 and 17 it can be seen that as the mean radiant and indoor air temperature increase, the PMV and PPD also increase, as would be expected.

However beyond $25^{\circ} \mathrm{C}$ the air temperature becomes less significant than other factors. This is most clearly observed in Figure 17, when at approximately 9:00, the indoor air 
temperature is constant, but the radiation level is still relatively high and the outside temperature is increasing. Such conditions lead to a reduction of heat loss to the surroundings, which in turn leads to an increase of heat gain by occupants for a short period of time. However, it is perhaps more important to note that the largest predicted increase in dissatisfaction occurs for the period where the mean radiant and indoor temperature increases above $25^{\circ} \mathrm{C}$ to its maximum (7:12 to 8:24).

FIGURE 16

FIGURE 17

\section{Discussion}

From examining the alternative solutions to improving thermal comfort in the office building, there are a number of clear findings. Firstly, the indoor air temperature appears to be the determining parameter of thermal comfort for all glazing systems up to $25^{\circ} \mathrm{C}$. Beyond this level, the incident radiation and outside temperature show some effect on thermal comfort but this appears to be less significant. For example, in the prediction of dissatisfaction behind the grey triple glazed facade, it was seen that with the indoor air temperature increasing from $25^{\circ} \mathrm{C}$ to approximately $27^{\circ} \mathrm{C}$, the PPD increased by over 20\%. However, for the same glazing with the indoor air temperature constant at approximately $27^{\circ} \mathrm{C}$, a reduction in incident radiation from $450 \mathrm{~W} / \mathrm{m}^{2}$ to $100 \mathrm{~W} / \mathrm{m}^{2}$ improved satisfaction by $10 \%$.

Similarly, for the shaded system, with the indoor air temperature being almost constant at $25^{\circ} \mathrm{C}$, there was a high degree of satisfaction predicted, whereas, in the case of the 
clear triple glazing, the high indoor temperature would suggest a high degree of thermal discomfort. As such control of the indoor temperature is paramount; however, reducing the incoming radiation, a driving factor for increased air temperatures, helps reduce the load that must be met by building services. In this regard the three tested systems help achieve this result.

Considering both the modelled and measured results, it is possible to draw some conclusions about the glazing systems. Firstly a system such as the shading screen could lead to improvements in thermal comfort (and energy efficiency) during summer periods, by reducing the solar gain through the windows. However, during cooler periods it would be ineffective in preventing heat losses from the building and could lead to occupants feeling cold.

Conversely, the use of triple glazed systems may be less effective in controlling solar and radiant heat gains however, they offer better insulating characteristics. When coupled with cooling in summer and heating in winter it is probable that the triple glazed systems would lead to greater stability in the thermal environment. Therefore, by reducing the fluctuations in the thermal environment it may be possible to achieve increased satisfaction from the occupants.

\section{Conclusion}

For many highly glazed buildings in Australia the thermal comfort of the occupants will be related to the incoming solar energy incorporated in the solar heat gain coefficient of 
the glazing. As conventional buildings tend to exhibit deep floor plans relative to their height, areas close to the facade receive a much greater amount of the incoming energy. This imbalance leads to occupants near the facade experiencing a high dissatisfaction with their thermal environment in the 'near-facade zone'.

This study utilised two software tools, VISION 3 (University of Waterloo, 1992) and WINDOW-6 (Lawrence Berkeley National Laboratory, 2011), to analyse and design a retrofit glazing system with a view to improving thermal environment of occupants near the glazed wall of a commercial office. In-situ testing of the glazing systems demonstrated that the simulation models provide a relatively good prediction of glazing temperatures for common glazing arrangements, and as such the heat transfer components.

Furthermore, the façade testing instrumentation allowed a quantitative analysis of the thermal environment using Fangers' predicted mean vote (PMV) and the predicted percentage dissatisfied (PPD). The findings of the modelling, testing and thermal comfort calculation provided some results leading towards improving the thermal environment in this 'near-facade zone'. It was found that control of the indoor temperature was paramount; however, it also showed that there are advantages to being able to reduce the incoming radiation directly, as well as to reduce the interior glass surface temperature through the use of static shading systems and advanced glazing systems. 


\section{Epilogue}

Since this study was undertaken, a retrofitting of the grey triple glazing system to the east façade has occurred, as requested by the offices' occupants. Anecdotal reports indicate that occupants are now comfortable with typical hot summer conditions and that the interior shading is only used to prevent glare on the computer screens for a few early hours. Furthermore, the 'near façade zone' that was previously used as a walkway is now fully occupied by workstations butting the glass façade. The buildings occupants have also reported that the new glazing installation has reduced the burden on the HVAC system and that desired set-point conditioning takes approximately 15 minutes to achieve. 


\section{References}

ASHRAE, (2005) 2005 ASHRAE Handbook-Fundamentals, American Society of Heating, Refrigerating, and Air-Conditioning Engineers Inc., Atlanta

Duffie, J.A. and Beckman, W.A. (2006) Solar engineering of thermal processes, Wiley, New York

Fang, Y., Hyde, T.J., and Hewitt, N. (2010) Predicted thermal performance of glazing, School of the Built Environment, University of Ulster, Newtownabbey

Fanger, P.O. (1973) Thermal comfort, McGraw-Hill, New York

International Standards Organisation (ISO), (2005) ISO 7730:2005 Ergonomics of the thermal environment -Analytical determination and interpretation of thermal comfort using calculation of the PMV and PPD indices and local thermal comfort criteria, International Organization for Standardization, Geneva

Lawrence Berkeley National Laboratory, (2011), http://windows.lbl.gov/software/window/6/index.html [cited 11/8/2011]

Liu, S.T., (1988), Temperature measurement of glass subjected to solar radiation, ASHRAE Transactions, 94 (2), 1359-1369 
Rowe, D.M., (2001) Activity rates and thermal comfort of office occupants in Sydney, Journal of Thermal Biology, Vol. 26 (4-5), 415-418

University of Waterloo, (1992), VISION 3.0, Glazing System Thermal Analysis, Advanced Glazing System Laboratory, University of Waterloo, Waterloo 


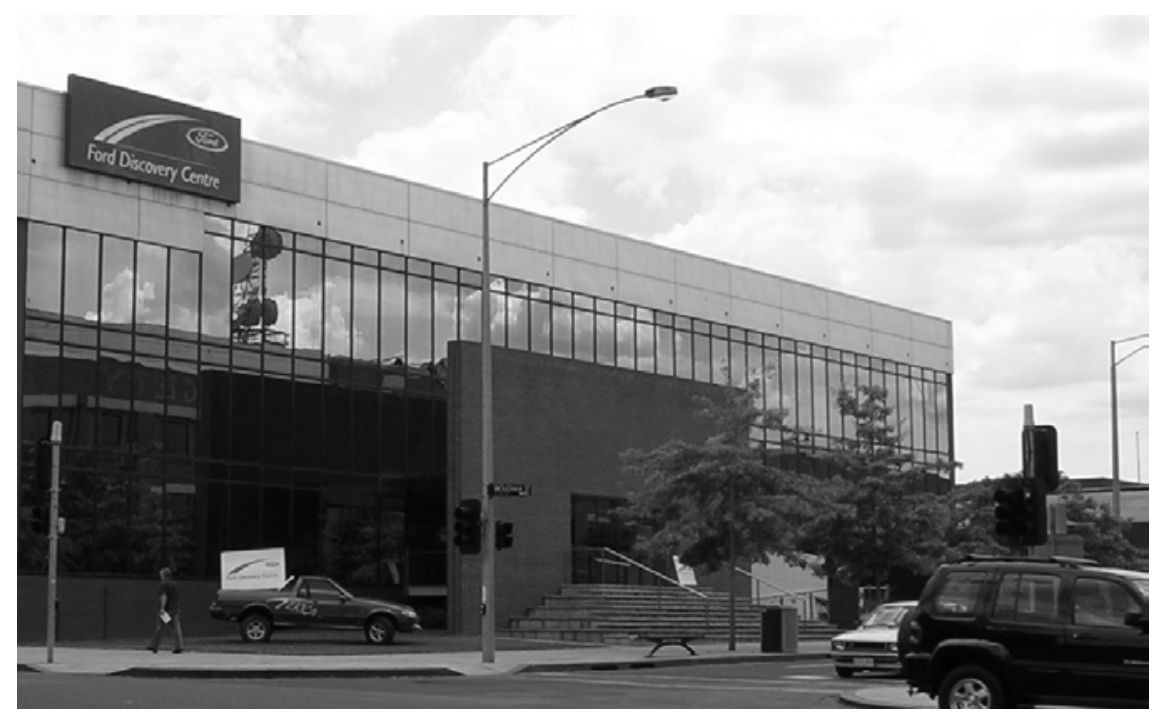

Figure 1: Eastern glazed facade of office building 


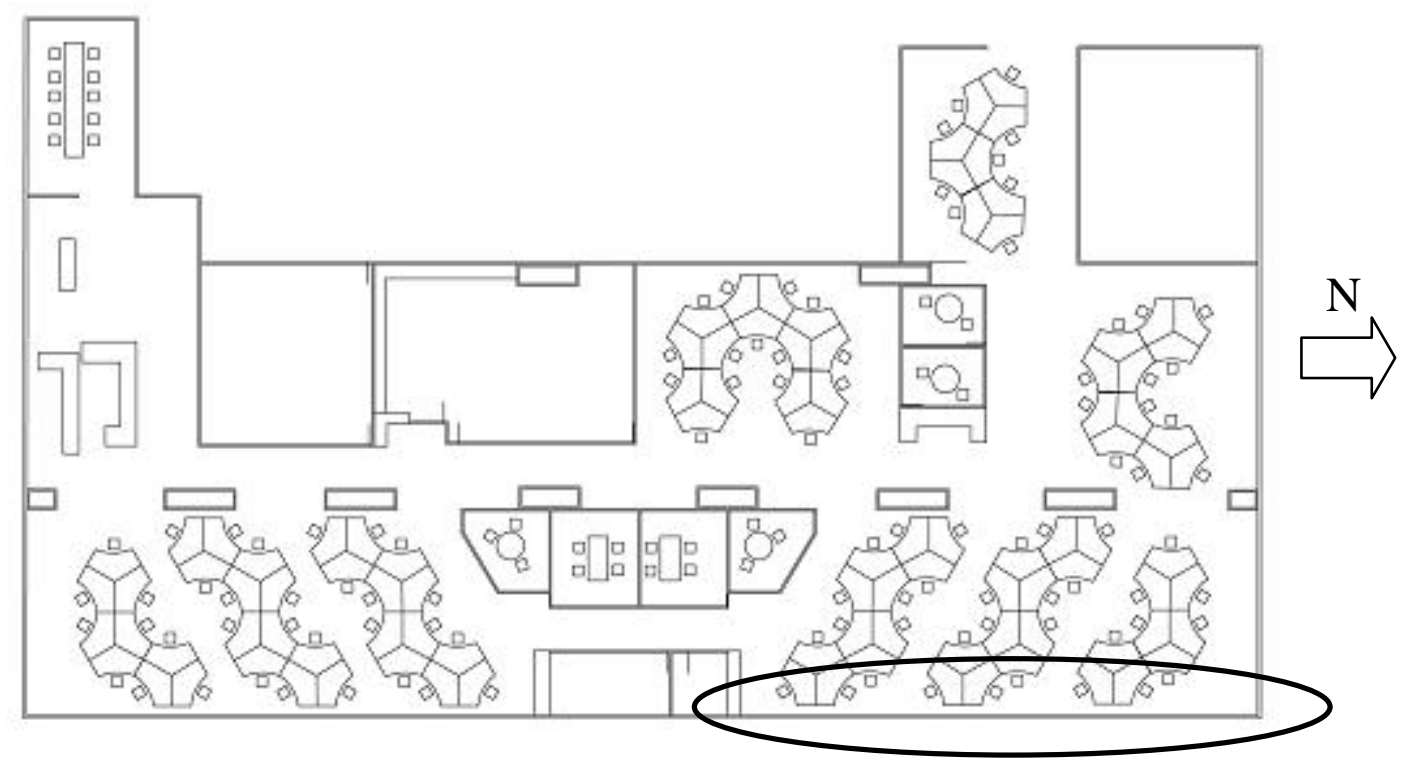

Figure 2: Office floor plan showing area of interest 


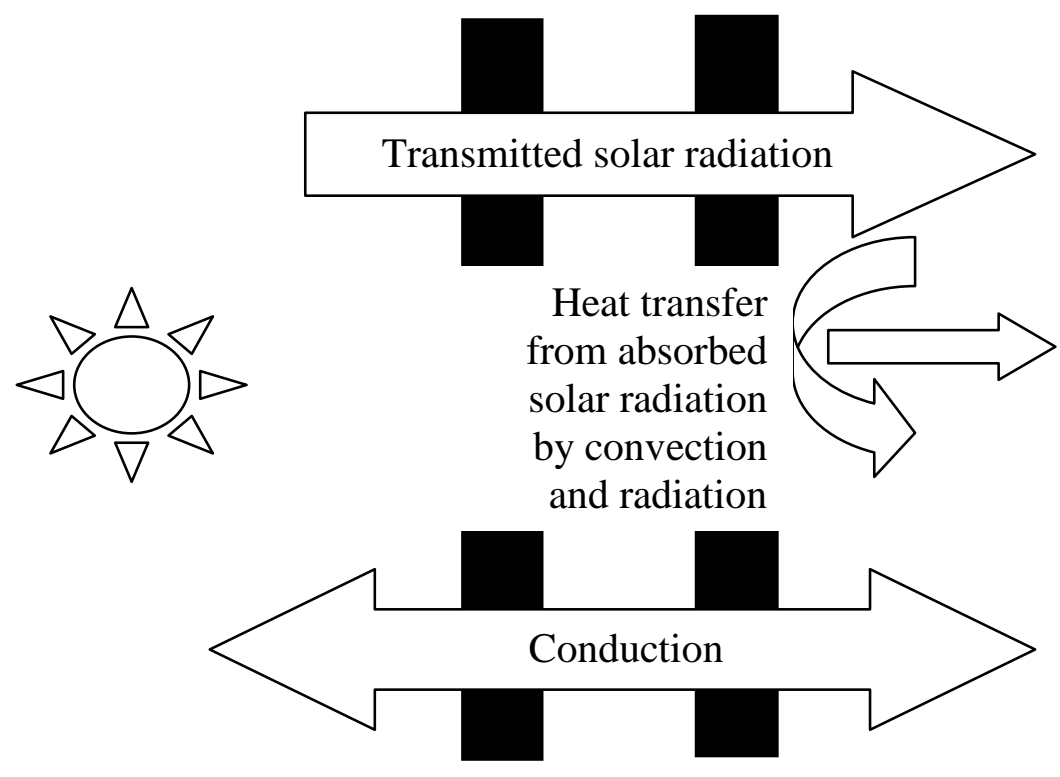

Figure 3: Heat transfer in a double glazed window 


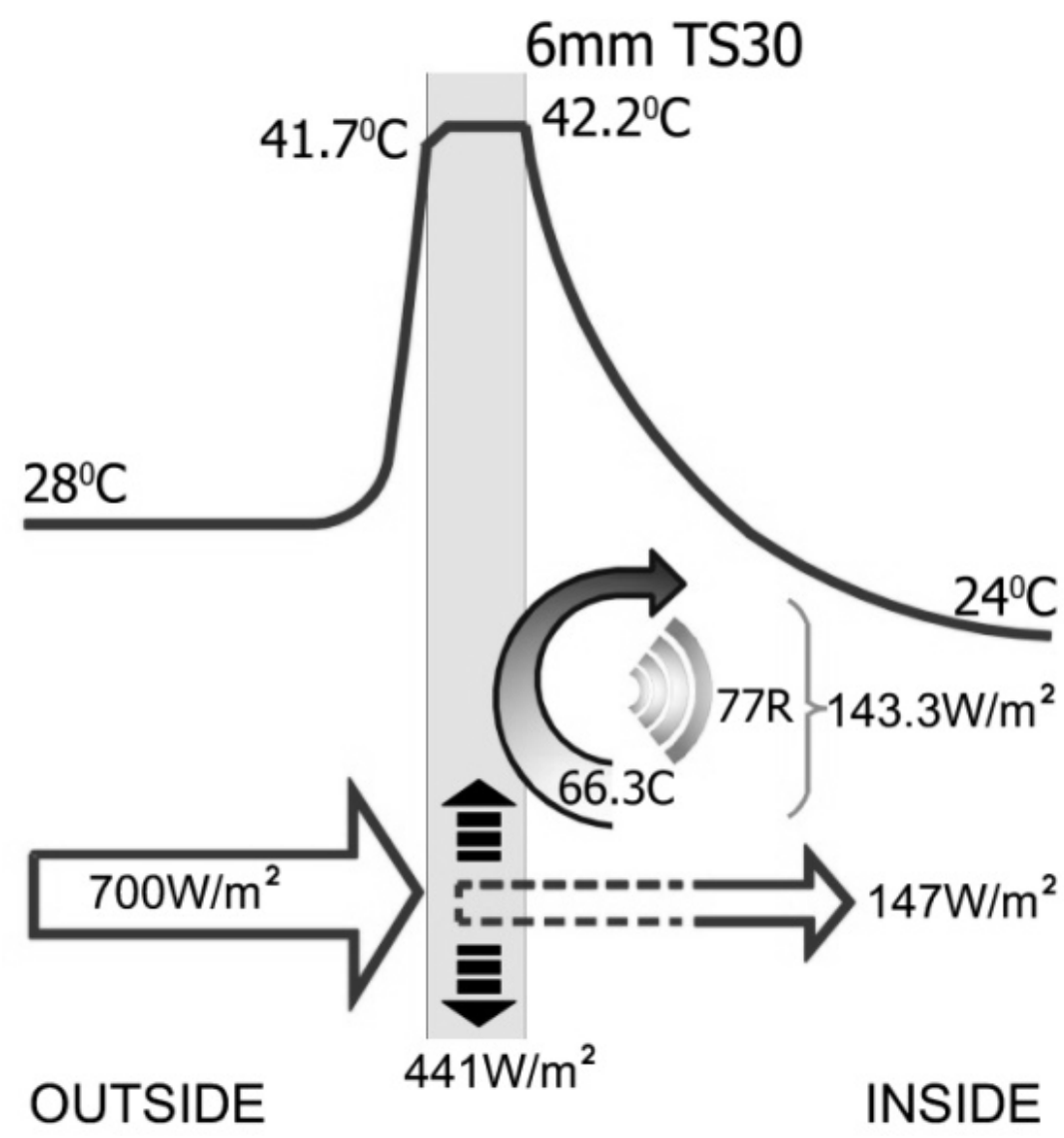

Figure 4: Heat transfer in single glazed system 


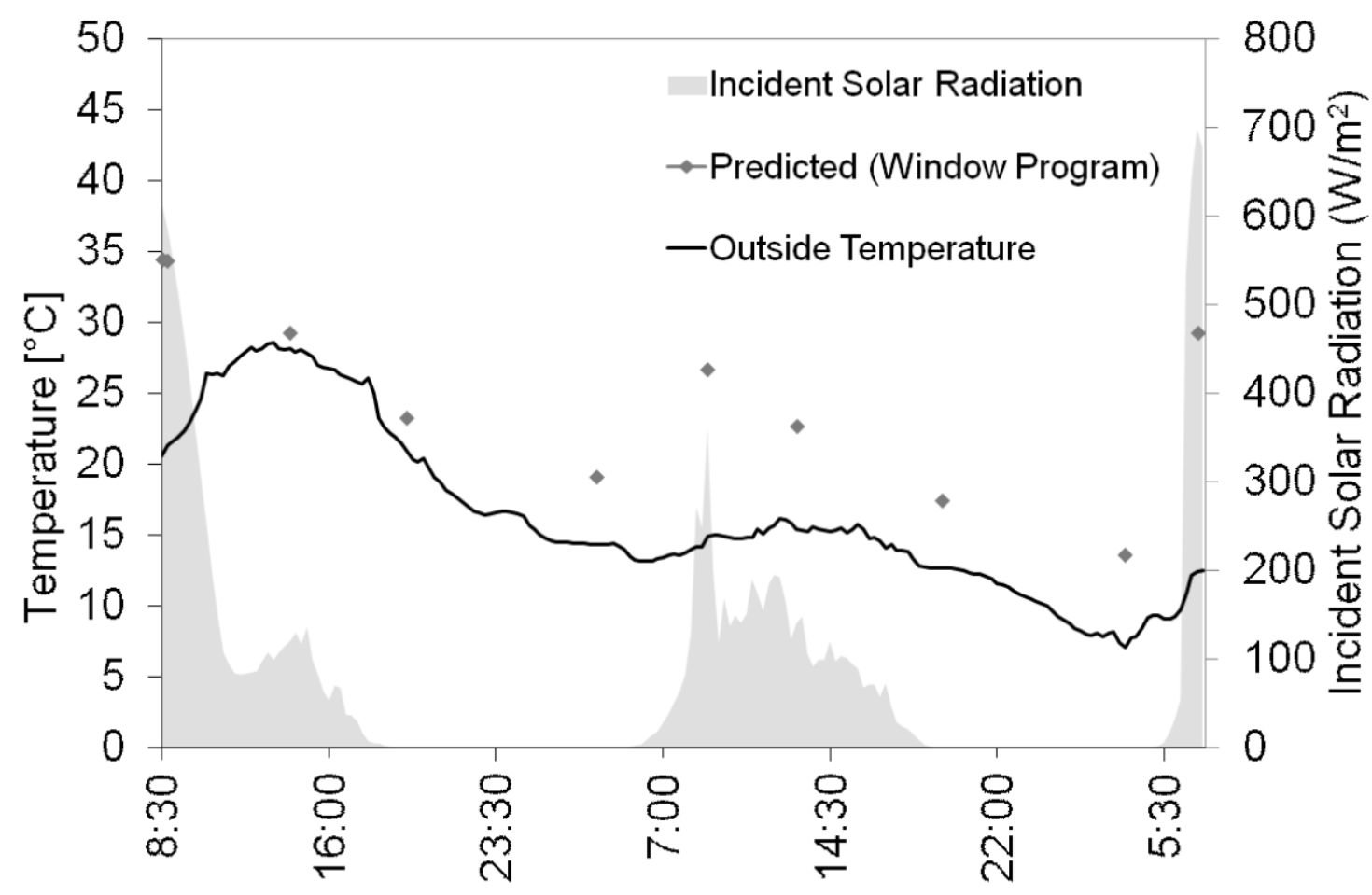

Figure 5: Predicted transient temperature of original single glazed system 


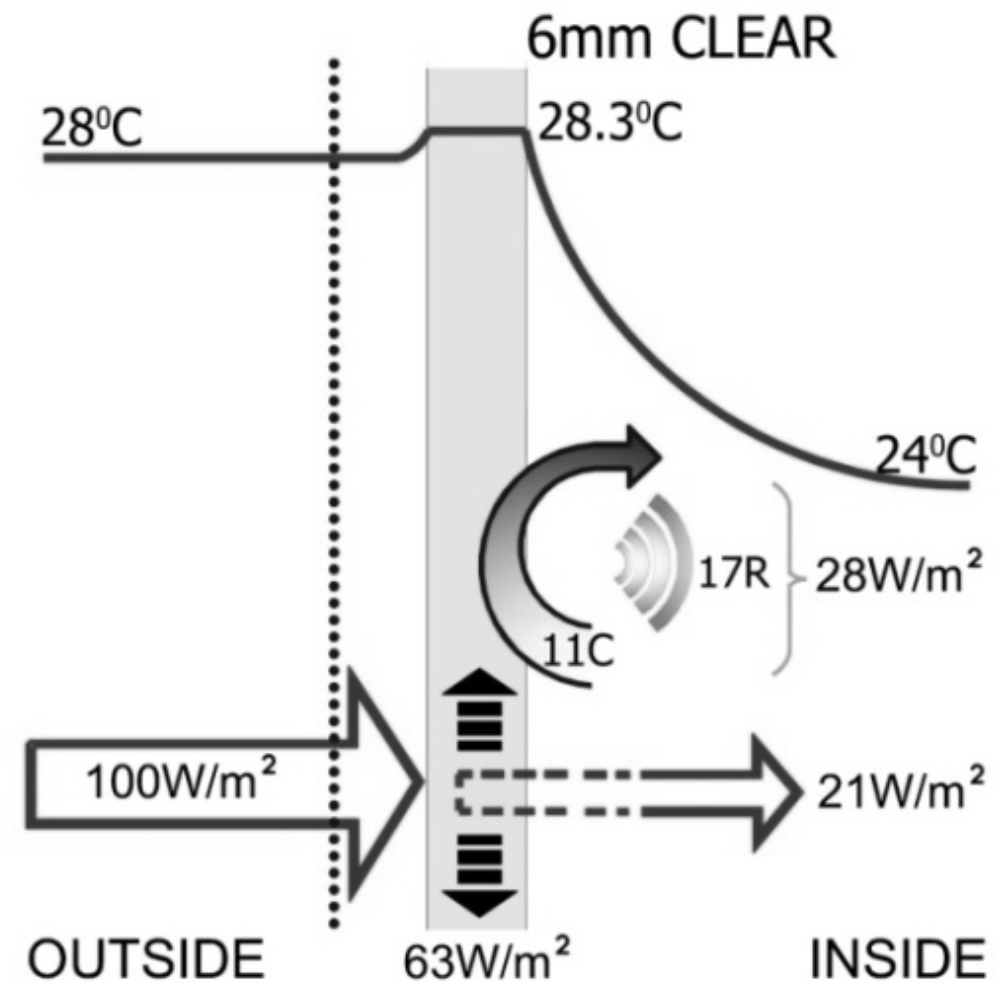

Figure 6 Heat transfer in shaded single glazed system 


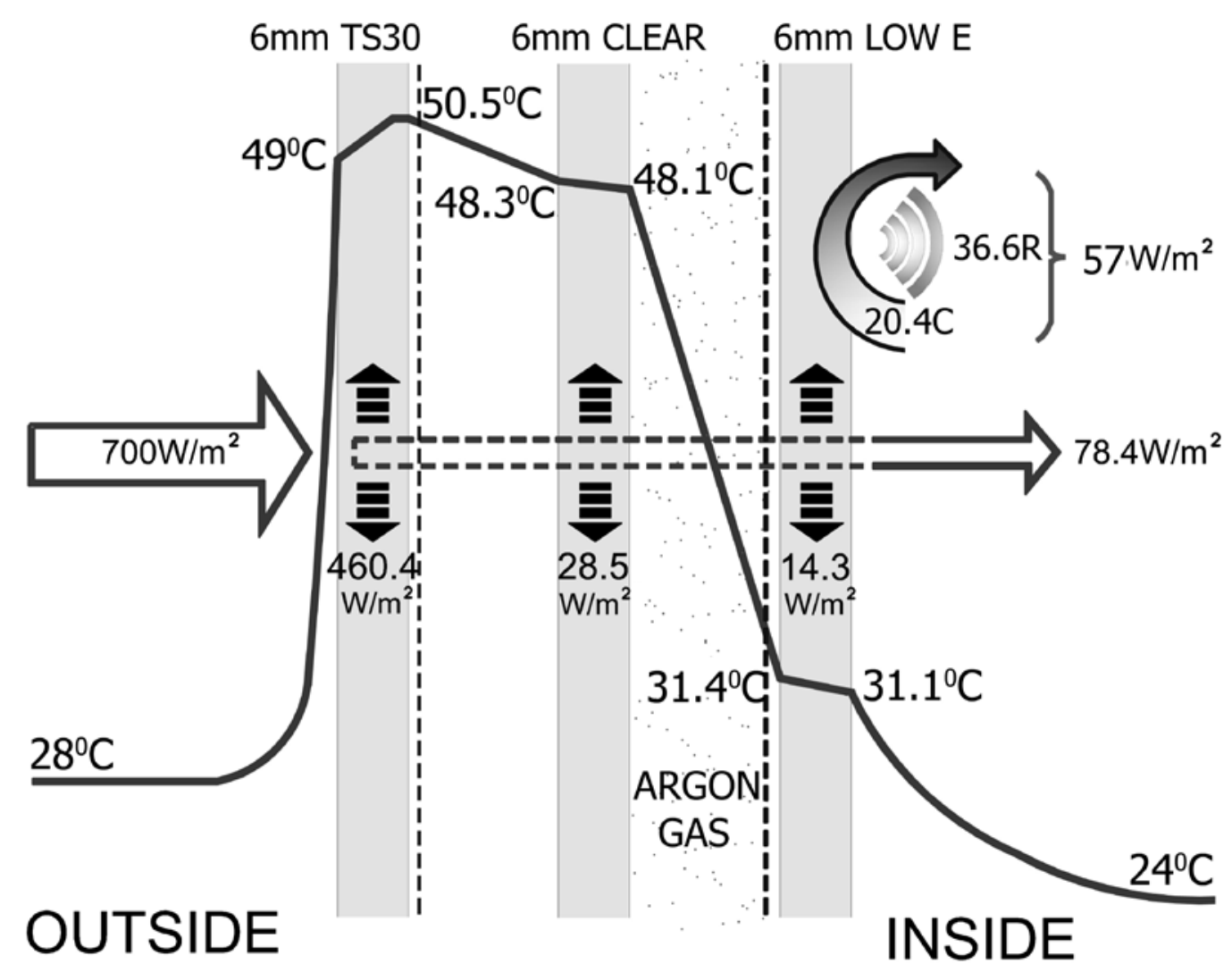

Figure 7: Heat transfer in clear triple glazed system 


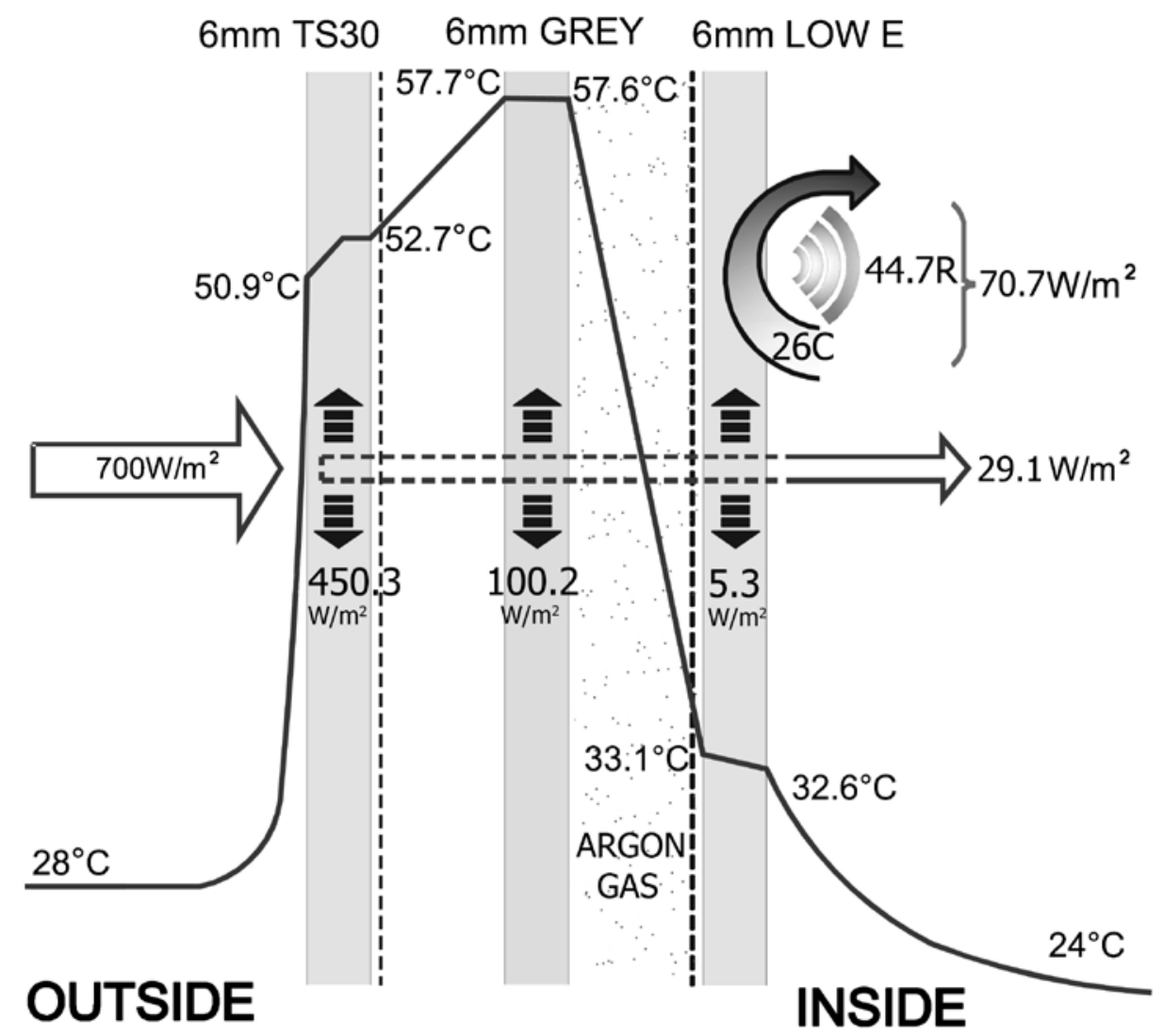

Figure 8: Heat transfer in grey glass triple glazed system 


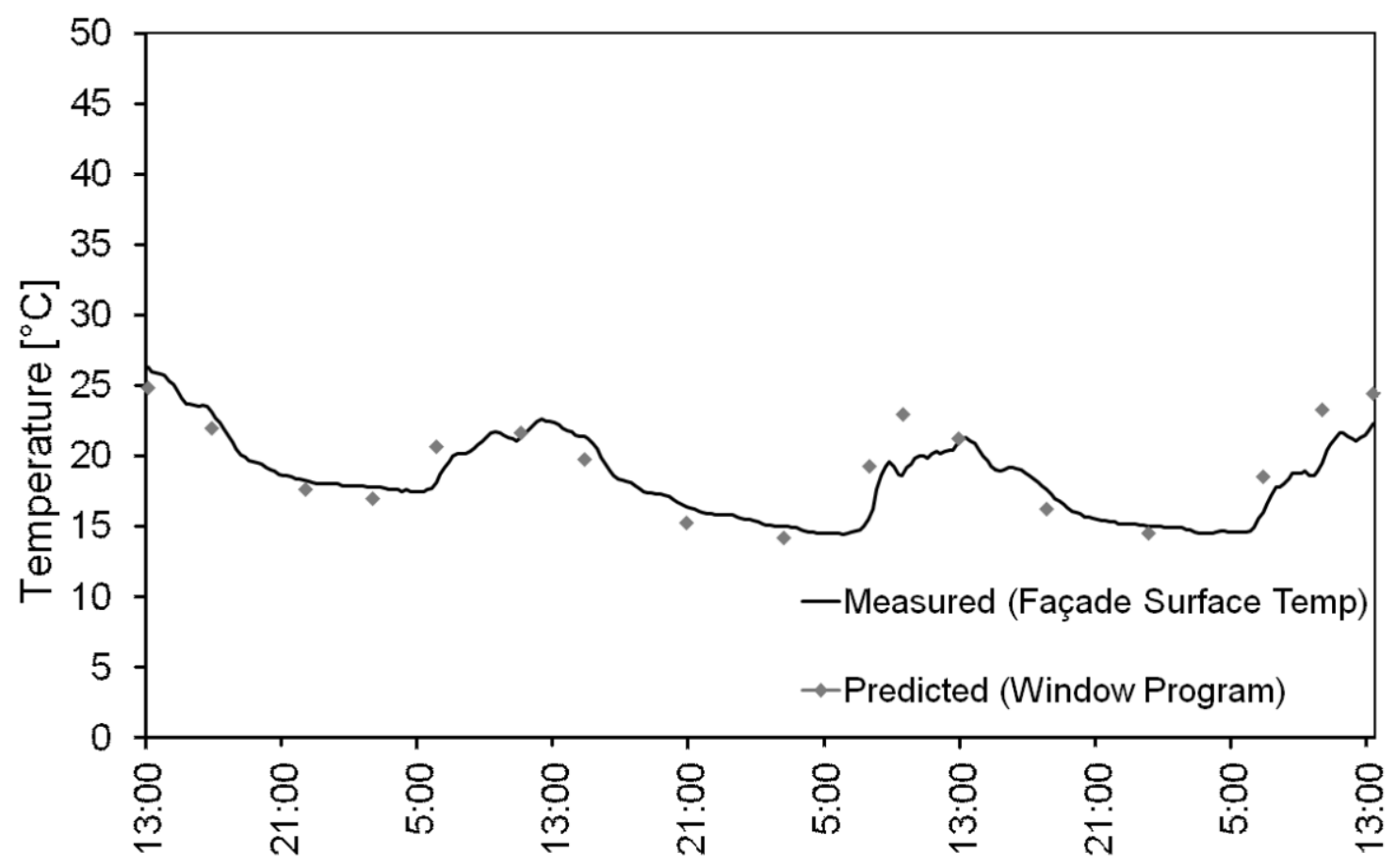

Figure 9: Predicted v Measured Glass Temperatures Inside Surface of Original Glazing System 


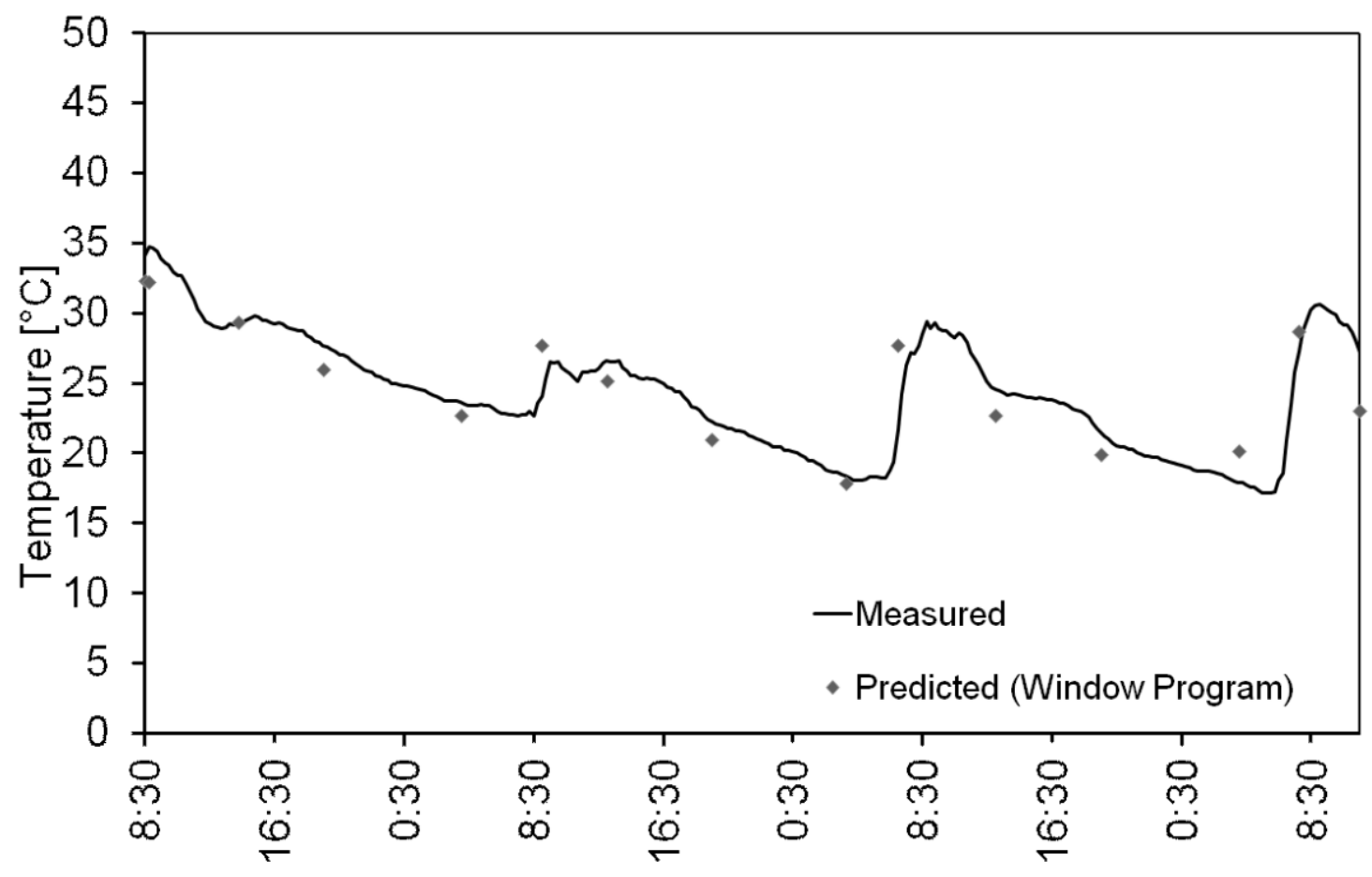

Figure 10: Predicted v Measured Glass Temperatures Inside Surface of Clear Triple Glazing 


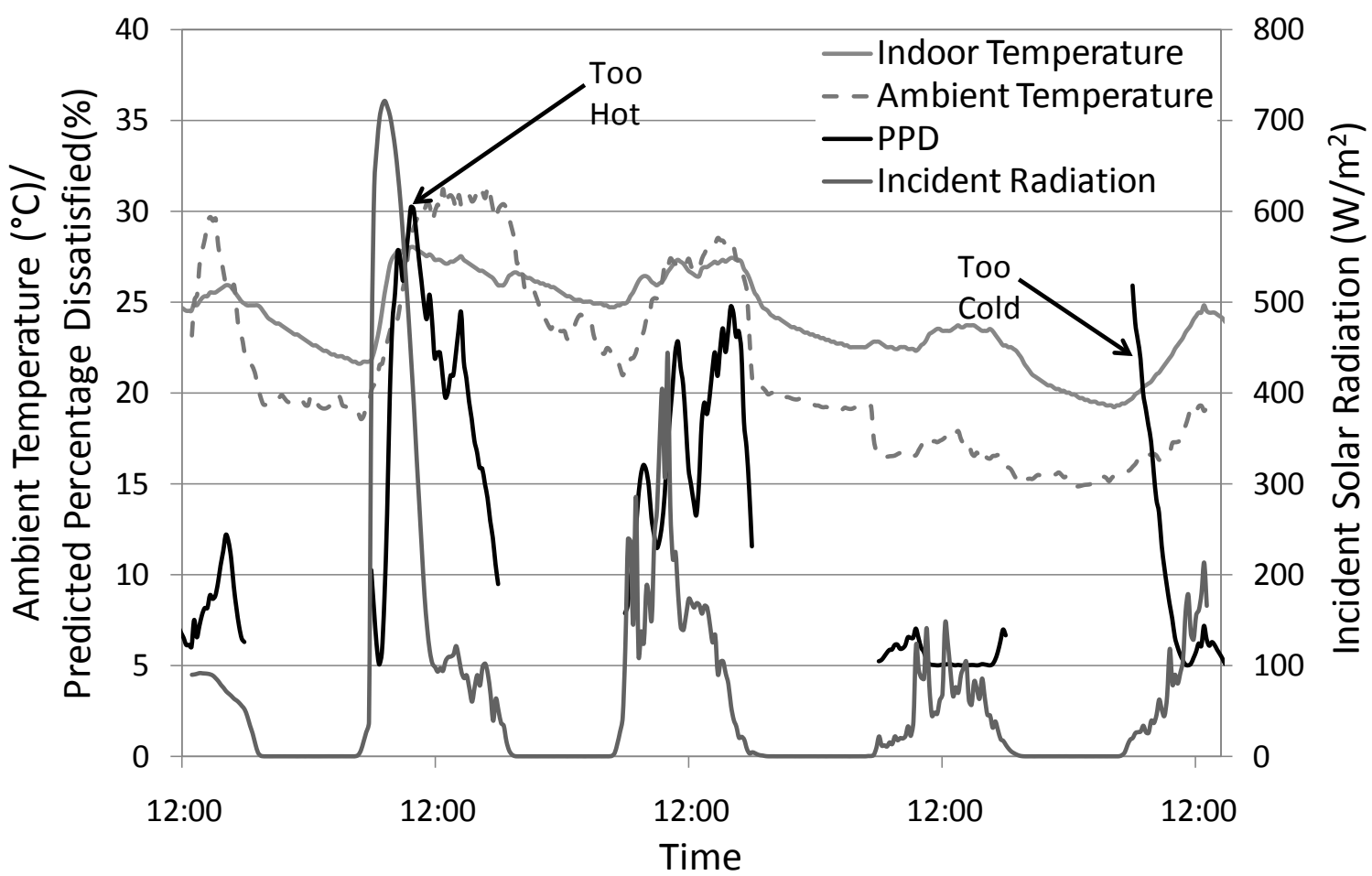

Figure 11: Predicted Percentage Dissatisfied (original glazing) 


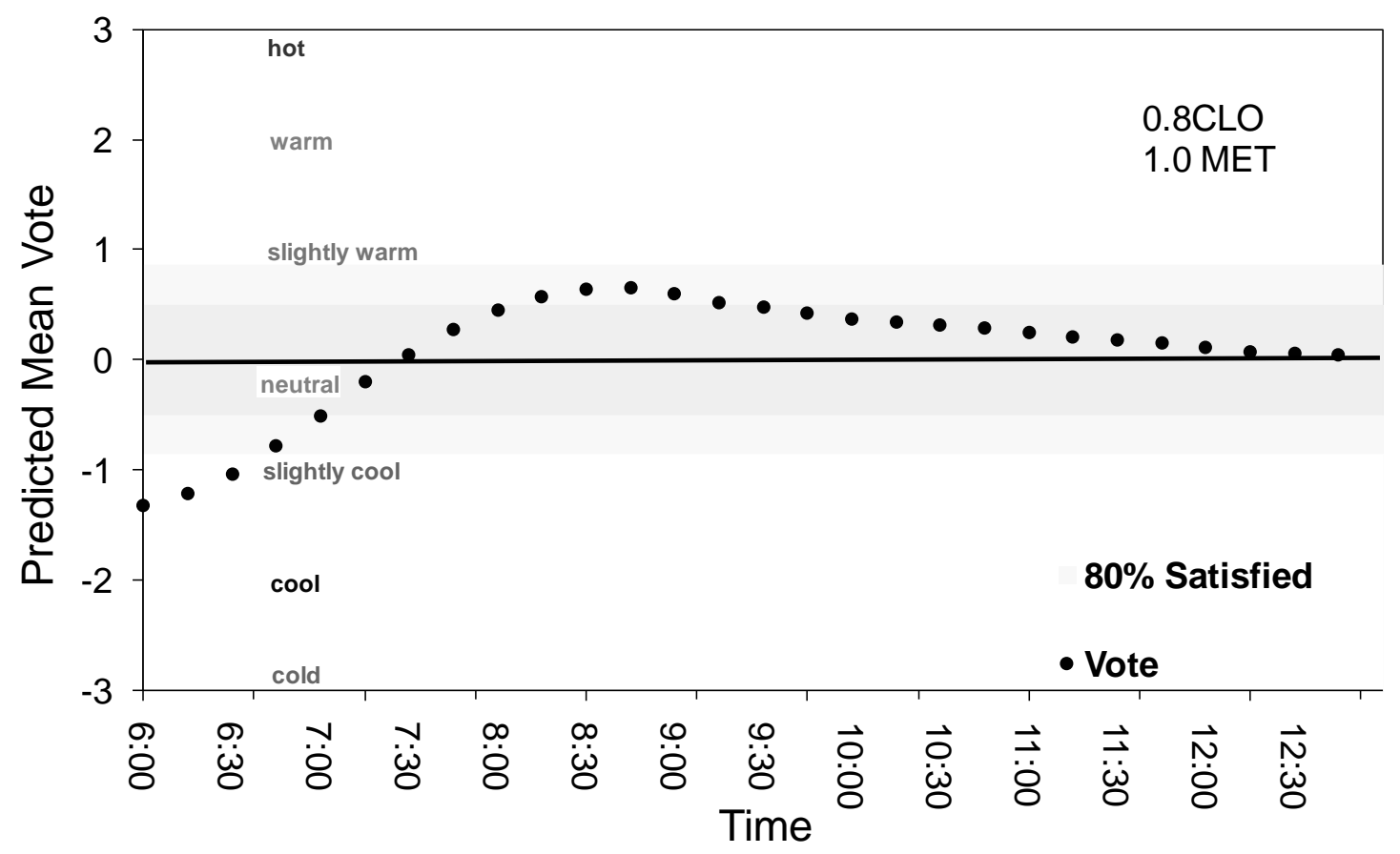

Figure 12: Predicted Mean Vote (shaded glazing) 


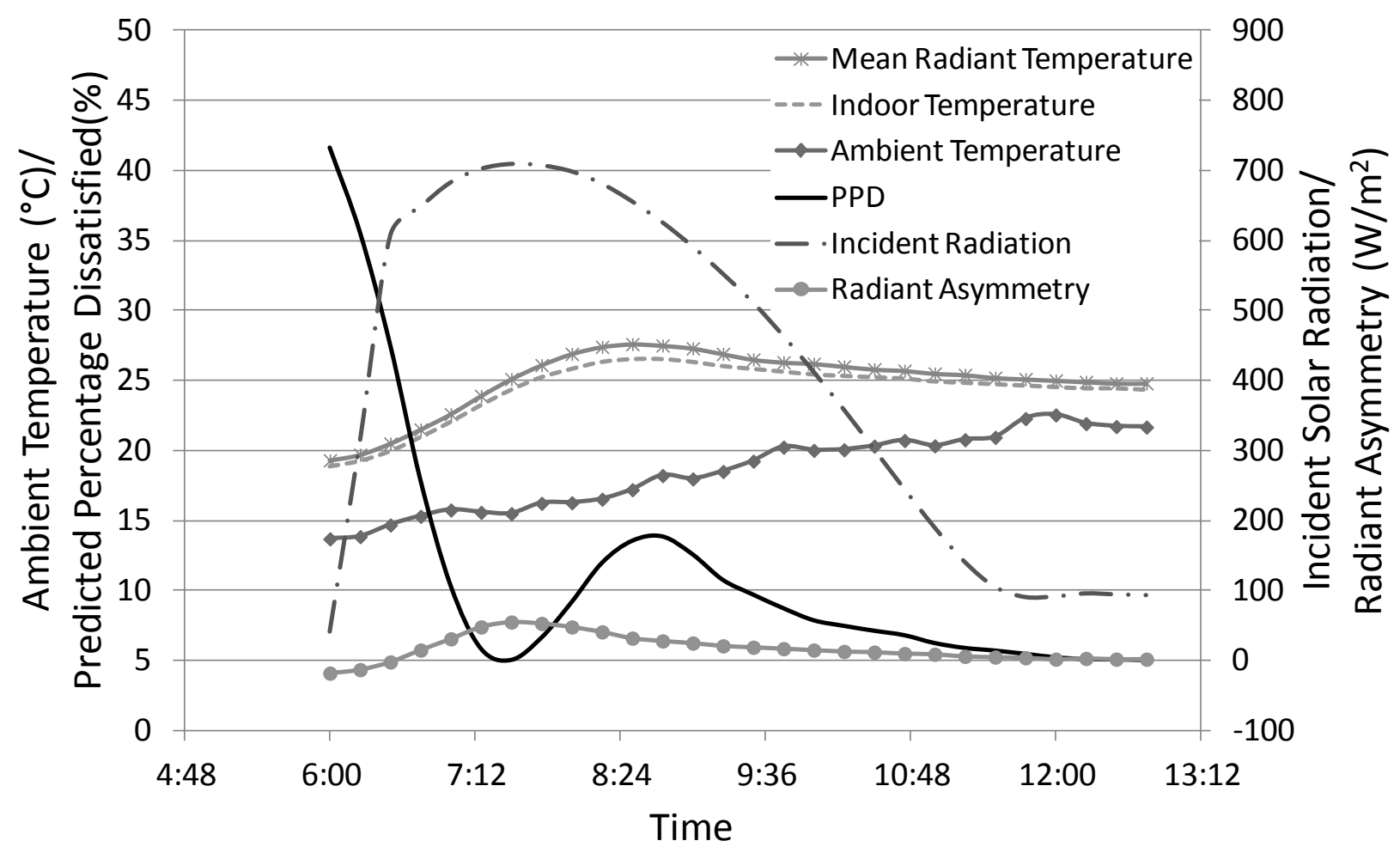

Figure 13: Predicted Percentage Dissatisfied (shaded glazing) 


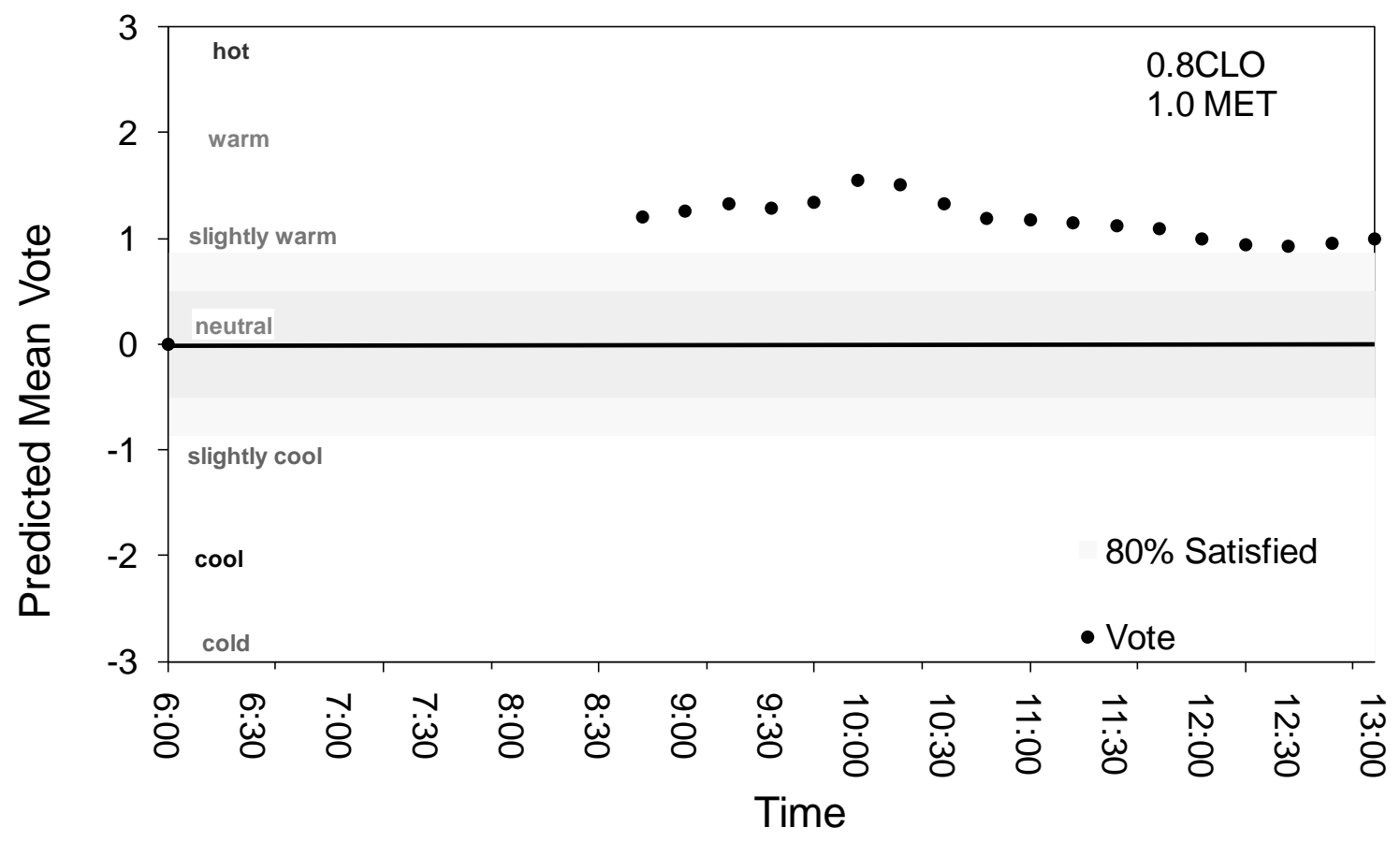

Figure 14: Predicted Mean Vote (clear triple glazing) 


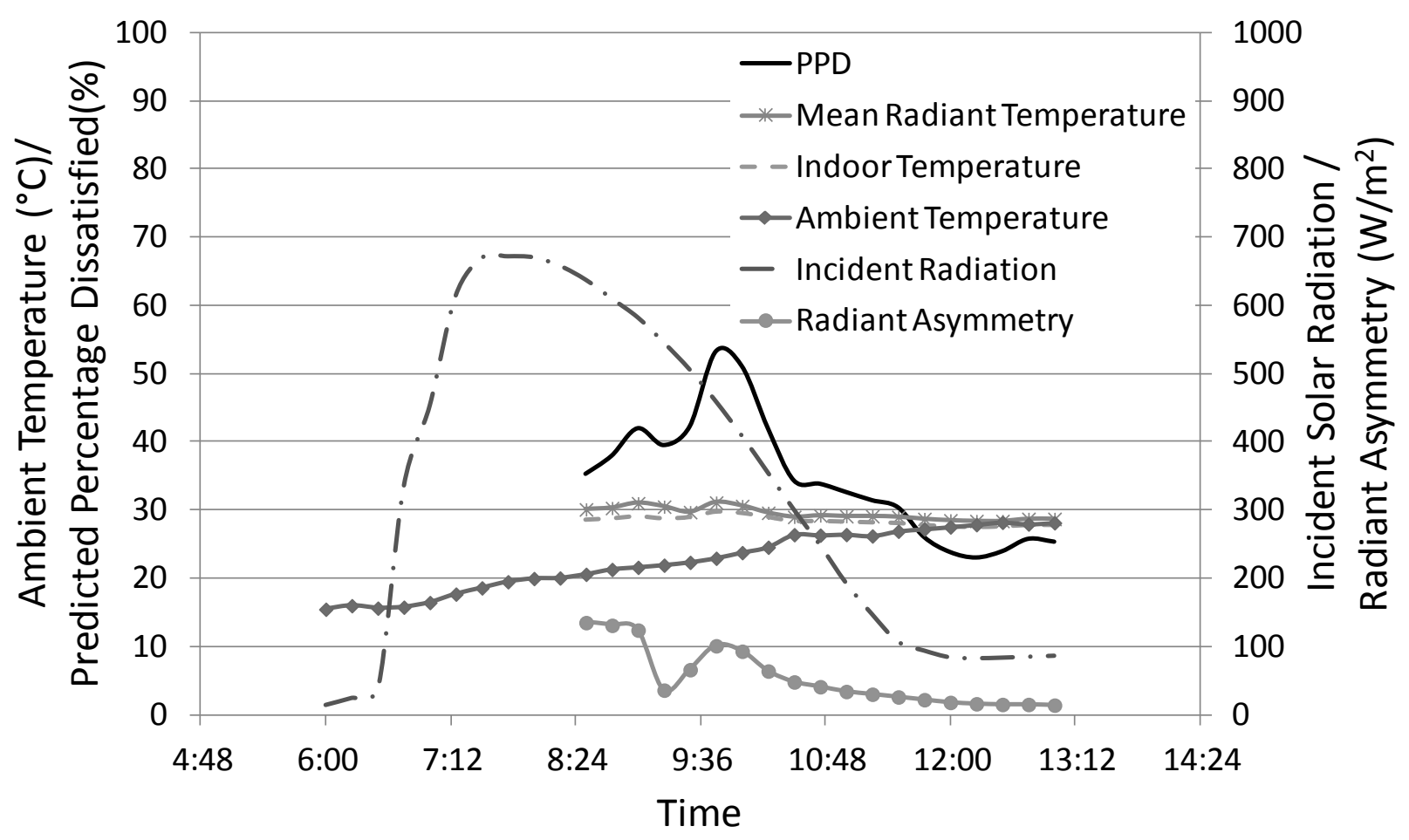

Figure 15: Predicted Percentage Dissatisfied (clear triple glazing) 


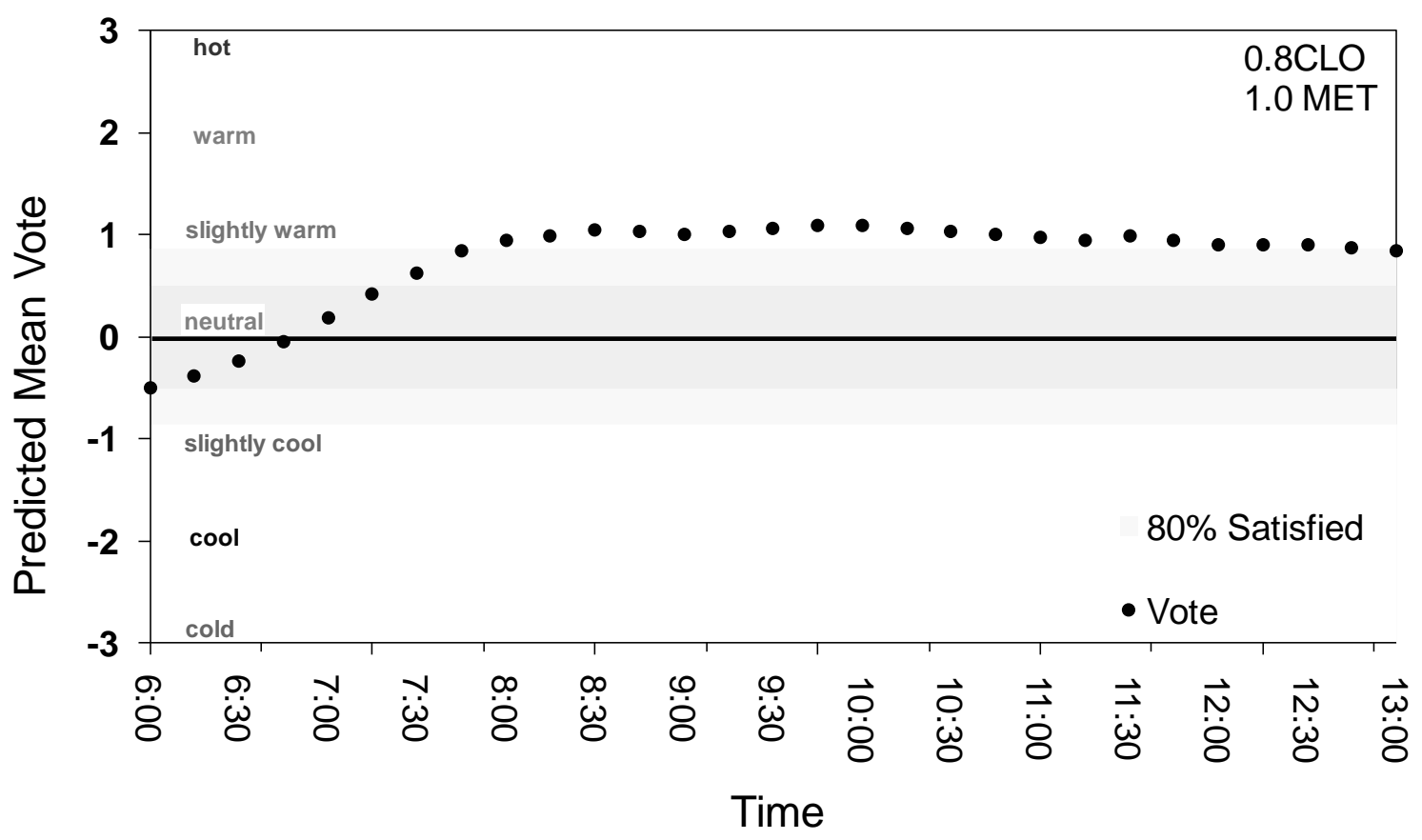

Figure 16: Predicted Mean Vote (grey triple glazing) 


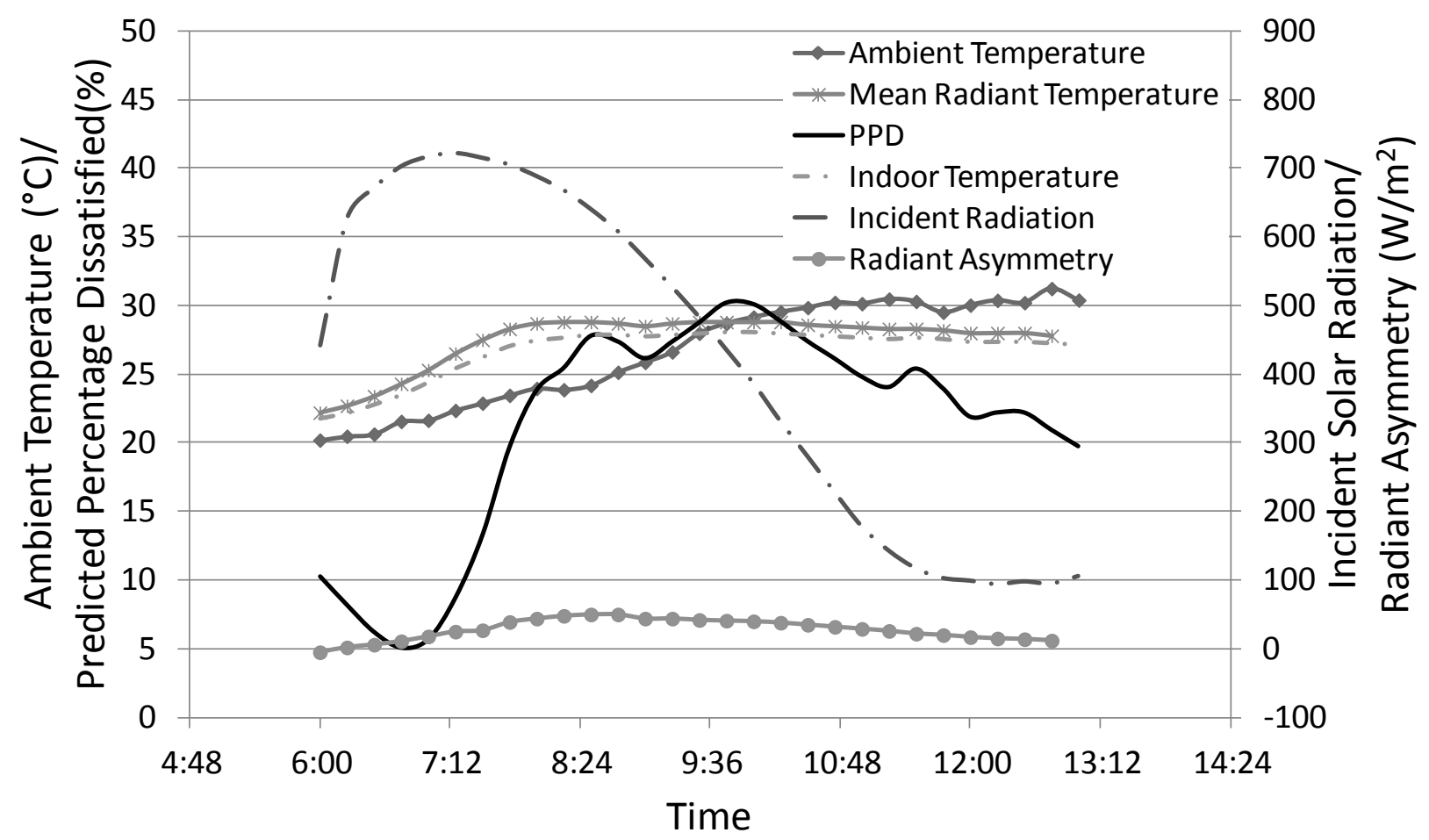

Figure 17: Predicted Percentage Dissatisfied (grey triple glazing) 
Table 1: Optical properties of single glazed system

\begin{tabular}{|c|c|c|c|c|c|c|}
\hline Glazing System & \multicolumn{2}{|c|}{ Visible } & \multicolumn{2}{c|}{ Solar } & \multicolumn{2}{c|}{ Longwave Reflectance } \\
\cline { 2 - 7 } Original Heat & $\tau \%$ & $\rho \%$ & $\tau \%$ & $\rho \%$ & Out \% & In \% \\
\cline { 2 - 7 } Absorbing Tinted Glass & 29 & 17 & 21 & 16 & 16 & 35 \\
\hline
\end{tabular}


Table 2: Optical properties of clear glass triple glazed system

\begin{tabular}{|c|c|c|c|c|c|c|}
\hline $\begin{array}{c}\text { Glazing System } \\
\text { Grey Triple } \\
\text { Glazed }\end{array}$ & \multicolumn{2}{|c|}{ Visible } & \multicolumn{2}{c|}{ Solar } & \multicolumn{2}{c|}{$\begin{array}{c}\text { Longwave } \\
\text { Reflectance }\end{array}$} \\
\cline { 2 - 7 } & $\tau \%$ & $\rho \%$ & $\tau \%$ & $\rho \%$ & Out \% & In \% \\
\hline Tinted Glass: & 29 & 17 & 21 & 16 & 16 & 35 \\
\hline Grey Glass: & 32 & 10 & 29 & 8 & 16 & 16 \\
\hline Low-E Glass: & 82 & 10 & 66 & $22 / 10$ & 84 & 16 \\
\hline
\end{tabular}


Table 3: Optical properties of grey glass triple glazed system

\begin{tabular}{|c|c|c|c|c|c|c|}
\hline $\begin{array}{c}\text { Glazing System } \\
\text { Clear Triple } \\
\text { Glazed }\end{array}$ & \multicolumn{2}{|c|}{ Visible } & \multicolumn{2}{c|}{ Solar } & \multicolumn{2}{c|}{$\begin{array}{c}\text { Longwave } \\
\text { Reflectance }\end{array}$} \\
\cline { 2 - 7 } & $\tau \%$ & $\rho \%$ & $\tau \%$ & $\rho \%$ & Out \% & In \% \\
\hline Tinted Glass: & 29 & 17 & 21 & 16 & 16 & 35 \\
\hline Clear Glass: & 87 & 7 & 77 & 7 & 16 & 16 \\
\hline Low-E Glass: & 82 & 10 & 66 & $22 / 10$ & 84 & 16 \\
\hline
\end{tabular}

